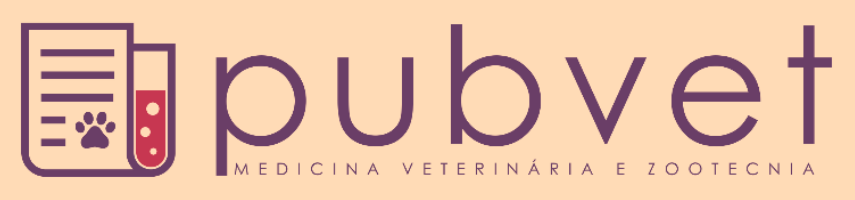

https://doi.org/10.31533/pubvet.v13n01a260.1-5

\title{
Levantamento de hemoparasitoses em cães e gatos no Hospital Veterinário Dr. Vicente Borelli - Aracaju - Sergipe
}

\author{
Andreza de Menezes Silveira ${ }^{1}{ }^{\bullet}$, Greice Maria Marques Menezes ${ }^{1} \bullet$, Alex da Silva Torquato \\ Júnior $^{1 \bullet}$, André Luiz da Conceição Santos ${ }^{1 *}{ }^{\bullet}$, Anne Izabella Sobreira Argolo Delfino ${ }^{2} \bullet$ \\ ${ }^{1}$ Discente do curso de Medicina Veterinária, Faculdade Pio Décimo, Aracaju, Sergipe, Brasil. \\ ${ }^{2}$ Docente do Curso de Medicina Veterinária e Médica Veterinária Responsável pelos Laboratórios de Patologia Clínica e \\ Microbiologia do Hospital Veterinário Dr. Vicente Borelli. \\ *Autor para correspondência: andrelouizst.al@gmail.com
}

Resumo. As hemoparasitoses formam um grupo de infecções causadas por microrganismos que acometem primariamente as células sanguíneas. Possuem ampla distribuição geográfica, tem como vetores carrapatos e mosquitos, acometem cães e gatos e possuem importância clínica e epidemiológica dado o quadro patológico que geram e seu potencial zoonótico. Esta pesquisa teve como objetivo realizar um levantamento de hemoparasitoses em cães e gatos no setor de Patologia Clínica do Hospital Veterinário Dr. Vicente Borelli em Aracaju, Sergipe, região de clima tropical. O projeto foi conduzido no Laboratório de Patologia Clínica pela confecção de lâminas pelo método de esfregaço sanguíneo e coloração rápida pelo panótico. As lâminas foram avaliadas sobre microscopia óptica em objetiva de 100X. Foram analisadas 100 lâminas, das quais em 23\%, entre amostras de cães e gatos, identificou-se a ocorrência de hemoparasitas caracterizando a confirmação de hemoparasitoses. Erlichia canis e Anaplasma platys foram os hemoparasitas de maior ocorrência neste estudo. Os resultados demonstraram que independentemente da raça, idade, sexo e manifestação clínica de sinais, todos os animais estão susceptíveis às infecções hemoparasitárias.

Palavras-chave: análises, hematologia, hemoparasitas

\section{Survey of hemoparasitosis in dogs and cats at Dr. Vicente Borelli Veterinary Hospital - Aracaju - Sergipe}

\begin{abstract}
Hemoparasitoses are a group of infections caused by microorganisms that primarily affect blood cells. They have a wide geographical distribution, have as vectors ticks and mosquitoes, affect dogs and cats and have clinical and epidemiological importance given the pathological picture they generate and their zoonotic potential. This research aimed to perform a survey of hemoparasitoses in dogs and cats in the clinical pathology sector of the Dr. Vicente Borelli Veterinary Hospital in Aracaju, Sergipe, a tropical climate region. The project was conducted in the laboratory of clinical pathology through the preparation of slides by the method of blood smear and rapid staining by the panótico, the slides were evaluated on optical microscopy in objective of 100X. A total of 100 slides were analyzed, of which in $23 \%$, between samples of dogs and cats, it was identified the occurrence of hemoparasites characterizing the confirmation of hemoparasitoses. Erlichia canis and Anaplasma platys were the most frequent hemoparasites in this study. The results demonstrated that regardless of race, age, sex and clinical manifestation of signs, all animals are susceptible to hemoparasitary infections.
\end{abstract}

Keywords: analysis, hematology, hemoparasites 


\title{
Levantamiento de hemoparasitosis en perros y gatos en el Hospital Veterinario Dr. Vicente Borelli - Aracaju - Sergipe
}

\begin{abstract}
Resumen. Las hemoparasitosis forman un grupo de infecciones causadas por microorganismos que afectan primariamente a las células sanguíneas. Tienen una gran distribución geográfica, tienen como vectores garrapatas y mosquitos, acomete perros y gatos y tienen importancia clínica y epidemiológica dado el cuadro patológico que generan y su potencial zoonótico. Esta investigación tuvo como objetivo realizar un levantamiento de hemoparasitosis en perros y gatos en el sector de patología clínica del Hospital Veterinario Dr. Vicente Borelli en Aracaju, Sergipe, región de clima tropical. El proyecto fue conducido en el laboratorio de patología clínica a través de la confección de láminas por el método de frotamiento sanguíneo y coloración rápida por el panótico, las láminas fueron evaluadas sobre microscopia óptica en objetivo de 100X. Se analizaron 100 láminas, de las cuales en un $23 \%$, entre muestras de perros y gatos, se identificó la presencia de hemoparásitos caracterizando la confirmación de hemoparasitosis. Erlichia canis y Anaplasma platys fueron los hemoparásitos de mayor ocurrencia en este estudio. Los resultados demostraron que, independientemente de la raza, edad, sexo y manifestación clínica de signos, todos los animales están susceptibles a las infecciones hemoparasitarías.
\end{abstract}

Palabras clave: análisis, hematología, hemoparásitos

\section{Introdução}

A aquisição de animais de companhia tem crescido nos últimos anos. Com isto, observa-se uma crescente da interação psicossocial entre o homem e o animal. Neste novo contexto, uma atenção especial é levantada, devido à elevada percentagem de doenças que afetam os animais de companhia e apresentam potencial zoonótico (Day, 2011).

Pode-se observar que na rotina clínica, grande parte das enfermidades é ocasionada por infecções hemoparasitárias, podendo ser causadas por protozoários, bactérias e/ou associação de ambos, que obrigatoriamente vivem no interior das células sanguíneas. Os principais agentes causadores das hemoparasitoses em animais de companhia são Babesia canis e Erlichia canis, hemoparasitas frequentemente diagnosticado em caninos, e o Mycoplasma haemofilis um hemoparasita de felinos. Ainda com frequência há ocorrência do Anaplasma platys, agente que leva perdas econômicas tanto em animais de produção quanto de companhia. A ocorrência de hemoparasitoses justifica-se pela ampla distribuição de seus vetores, carrapatos e mosquitos no ambiente rural e urbano, sobretudo em regiões de clima tropical (Radostits et al., 2010).

Dado a importância das hemoparasitoses no contexto clínico, objetivou-se realizar o levantamento casuístico destas enfermidades na rotina do Hospital Veterinária Dr. Vicente Borelli, em Aracaju Sergipe,durante um período de doze meses pela visualização em lâminas de esfregaços sanguíneo.

\section{Material e métodos}

O estudo conduziu-se no período de 12 meses, iniciando em setembro de 2017 e concluído em setembro do ano subsequente. Neste período, avaliaram-se amostras sanguíneas pela confecção de esfregaços sanguíneos de 100 animais, 80 cães e 20 gatos. As amostras sanguíneas avaliadas, eram enviadas ao Laboratório de Patologia Veterinária em tubo com anticoagulante (EDTA) identificadas segundo os parâmetros de nome, idade, raça, sexo, espécie e registro do animal. Uma alíquota das amostras era separada, enquanto o restante seguia para análise clínica da rotina hospitalar. Para a realização do esfregaço sanguíneo, depositou-se por meio de capilar uma gota de sangue nas lâminas, e com o auxílio de uma extensora realizou-se o esfregaço. O método de coloração escolhido foi o panótico e a padronização dos tempos de coloração foi de 5, 10 e 15 segundos nos respectivos corantes. A leitura microscópica das lâminas foi realizada em objetiva 100X com o auxílio do óleo de imersão, na qual uma gota era depositada sobre as lâminas avaliadas. Lâminas positivas foram fotografadas (Figura 1). 


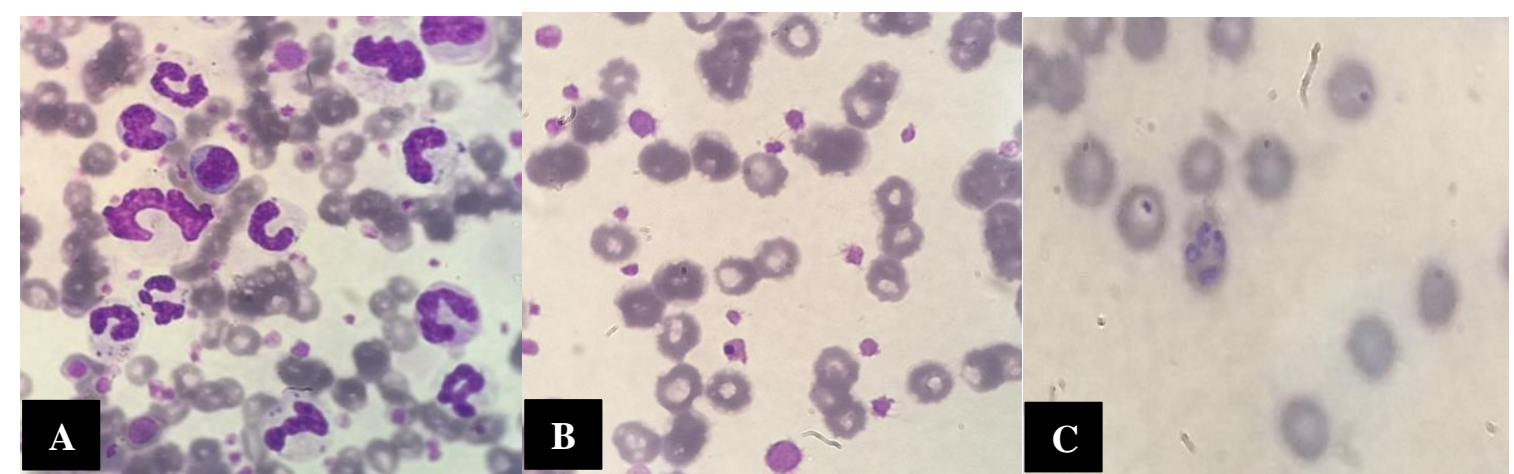

Figura 1. Imagens microscópicas de hemoparasitas de lâminas coradas pelo método panótico. Na sequência tem-se Erliquia canis (A), Anaplasma platys (B) e Babesia canis $(\mathbf{C})$.

\section{Resultados e discussão}

Das 100 lâminas analisadas, 23 (23\%) apresentaram hemoparasitas, sendo 10 (10\%) positivas para Erlichia canis; 5 (5\%) positivas para Babesia canis; 7 para Anaplasma platys e 1 (1\%) positiva para Mycoplasma haemofelis. Setenta e sete por cento das lâminas obtiveram resultado negativo quanto à presença de hemoparasitas nas amostras avaliadas (Figura 2). Dos 23 animais acometidos, 2 eram felinos e 21 caninos de ambos os sexos.

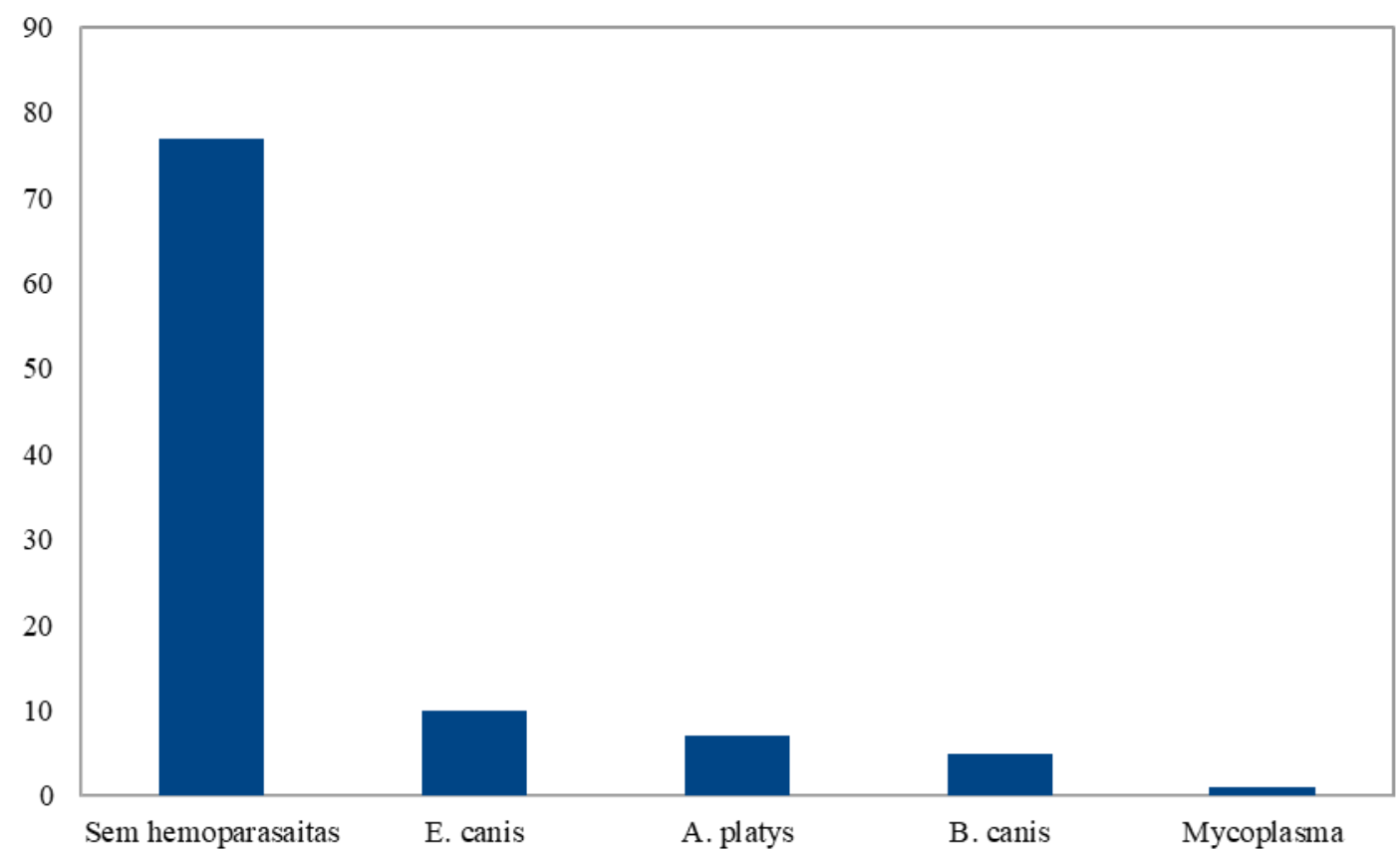

Figura 2. Quantidade total de lâminas analisadas no estudo e os respectivos resultados da identificação de hemoparasitas.

Pelo esfregaço sanguíneo detectou-se em maioria a presença de E. canis, resultado que difere daquele achado por Mundim et al. (2008) em Anápolis-GO, que encontrou 34\% de amostras positivas para hemoparasitas com menor incidência de E. canis. Waner et al. (1995) relatam uma maior ocorrência de E. canis identificadas em esfregaços. Todavia, a pesquisa realizada encontrou uma quantidade considerável de além delas, A. platys. Em outro estudo realizado na região centro-oeste do país por Salgado (2006), não foi encontrada infecção por A. platys, apesar do alto índice de positividade geral para hemoparasitos $(62 \%)$.

Na pesquisa de Costa (2011) o B. canis foi o terceiro hemoparasita de maior ocorrência acometendo os cães, tendo a infecção por E. canis e A. platys uma maior prevalência, o que difere-se do estudo realizado na região centro-oeste do país por Salgado (2006), onde a maior prevalência encontrada foi de E. canis identificada em $60,5 \%$ dos animais, seguida por B. canis, encontrada em $10,8 \%$. 
Quanto ao Mycoplasma haemofelis, apenas a amostra de 1 felino (1\%) apresentou o hemoparasita. Todavia, há relatos de taxas de infecção por hemoplasmas superior ao observado nesta pesquisa, as quais foram detectadas por esfregaço sanguíneo. Como, exemplo, os 38\% reportado por Mendes-de-Almeida (2004) no Rio de Janeiro e 26,6\% reportado por Miranda (2008), em Belém. Devido à dificuldade em visualizar Mycoplasma, a técnica de PCR e sequenciamento devem ser empregados para evitar resultados indesejáveis como falsos positivos ou falsos negativos (Sykes, 2010).

Não se evidenciou microfilárias de Dirofilaria immitis, nos esfregaços sanguíneos. Dos 23 animais infectados, os casos foram mais frequentes em animais fêmeas, de 1 a 5 anos de idade e de raça definida (Figura 3). Quanto à idade dos animais como fator condicionante para as hemoparasitoses não houve padrões observados.

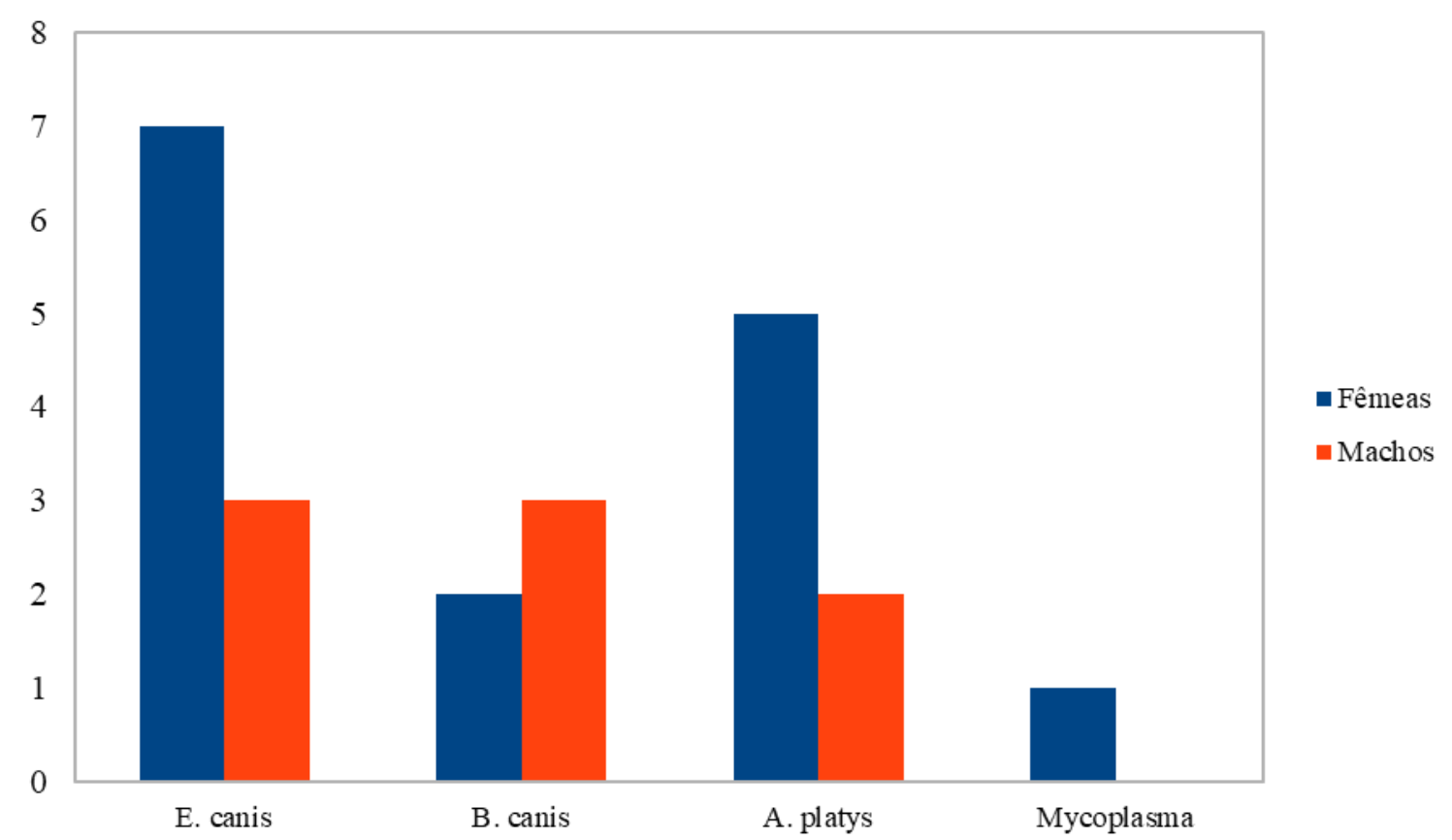

Figura 3. Índice de infectados por hemoparasitas relacionados ao sexo dos animais no período de realização do estudo.

\section{Referências bibliográficas}

Costa, H. X. (2011). Interação de hemoparasitos e hemoparasitoses em casos clínicos de trombocitopenia em cães no município de Goiânia. Masster of Science, Universidade Federal do Goiás, Goiânia, Goiás, Brasil.

Day, M. J. (2011). One health: the importance of companion animal vector-borne diseases. Parasites \& Vectors, 4(49), 1-6.

Mendes-de-Almeida F., Faria M.C.F., Branco A.S., Serrão M.L., Souza A.M., Almosny N., Chame M. \& Labarthe N. (2004). Sanitary conditions of a colony of urban feral cats (Felis catus Linnaeus, 1758) in a zoological garden of Rio de Janeiro, Brazil. Revta Inst. Med. Tropical, 46(5), 269-274.

Miranda, C. F. (2008). Prevalência de Mycoplasma haemofelis (Hemobartonella felis) em gatos domésticos (Felis catus Linaeus, 1759) na região metropolitana de Belém. Master of Science, Universidade Castelo Branco, Belém, Pará, Brasil.

Mundim, E. C. S., Francisco, M. M. S., Souza, J. N., Alencar, M. A. G. \& Ramalho, P. C. D. (2008). Incidência de hemoparasitoses em cães (Canis familiares) de rua capturados pelo Centro de Controle de Zoonoses (CCZ) da cidade de Anápolis-GO. Ensaios e Ciência: Ciências Biológicas, Agrárias e da Saúde, 12(2), 108-114.

Radostits, O. M., Gay, C. C., Blood, D. C., Hinchcliff, K. W. \& McKenzie, R. A. (2010). Clínica Veterinária: um tratado de doenças dos bovinos, ovinos, suínos, caprinos e eqüinos (Vol. 1). Rio de Janeiro: Guanabara Koogan. 
Salgado, F. P. (2006). Identificação de hemoparasitos e carrapatos de cães procedentes do Centro de Controle de Zoonoses de Campo Grande, Estado do Mato Grosso do Sul, Brasil. PhD, Universidade Federal do Mato Grosso, Campo Grande, Mato Grosso, Brasil.

Sykes, J. E. (2010). Feline hemotropic mycoplasmas. Journal of Veterinary Emergency and Critical Care, 20(1), 62-69.

Waner, T., Harrus, S., Weiss, D. J., Bark, H. \& Keysary, A. (1995). Demonstration of serum antiplatelet antibodies in experimental acute canine ehrlichiosis. Veterinary Immunology and Immunopathology, 48(1-2), 177-182.

Recebido: 8 dezembro, 2018 .

Aprovado: 8 janeiro, 2019.

Publicado: 30 janeiro, 2019.

Licenciamento: Este artigo é publicado na modalidade Acesso Aberto sob a licença Creative Commons Atribuição 4.0 (CC-BY 4.0), a qual permite uso irrestrito, distribuição, reprodução em qualquer meio, desde que o autor e a fonte sejam devidamente creditados. 